\title{
Radioastronomers hope for world observatory
}

Washington. The cost of future radio telescopes implies that an international consortium will be needed to build them, astronomers say. But several large obstacles will have to be overcome, particularly if the richest countries - the United States and Japan - are to be involved in such a collaboration.

Ideally, a World Radio Astronomy Observatory (WRAO) would operate along the lines of the US National Radio Astronomy Observatory, with a small central bureaucracy overseeing a facility open to all astronomers from anywhere in the world.

But the political problems are daunting. Most national governments would expect their scientists to get a guaranteed fraction of time at a telescope, in return for their financial contribution. This is not the way to get the best science from the facility - but few countries are rich enough to share the United States view, that access should be based on scientific merit alone. This causes friction whenever the US is involved, because American scientists take for granted that every facility will be open. And if Japan is involved, extra costs associated with the Japanese method of doing big science become a problem.

At last month's conference on "Radio astronomy visions for the 21 st century" at Penticton, British Columbia, astronomers gathered to ponder which big problems remain in their discipline, and what instruments they need most.

They agreed that the most interesting problems are "when and how do galaxies form?", and "what does their early evolution look like?" But the answers to these questions will not come cheap. The next generation of radio telescopes will cost $\$ 150$ $\$ 300$ million to build, and \$5-\$15 million per year to operate. This led Ron Ekers, director of the Australia Telescope National Facility, to suggest that it was time to consider founding - and funding — a World Radio Astronomy Observatory.

Two projects widely acclaimed at Penticton could potentially fit the bill. Roy Booth, director of the Onsala Space Ob-

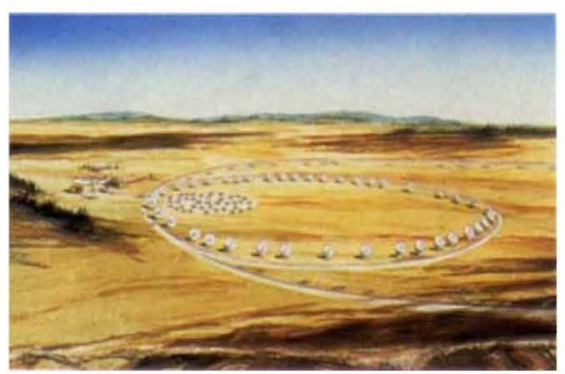

The $\$ 150$ million millimetre-wave array: under consideration at NSF.

servatory in Sweden, proposes an array of forty 15 -metre - or ninety 10 -metre telescopes operating as an interferometer at wavelengths from $0.8 \mathrm{~mm}$ to $3 \mathrm{~mm}$, and located in Chile. Booth says that with current technology this would cost $\$ 250$ million to construct, but hopes that better antenna design would bring the price down to $\$ 150$ million.

Robert Braun, of the Netherlands Foundation for Research in Astronomy, suggests a phased-array telescope with a total collecting area of $1 \mathrm{~km}^{2}$, operating at wavelengths from about $21 \mathrm{~cm}$ to 1.5 metre, and primarily studying emission from atomic hydrogen. The detectors, if located in the Netherlands, would be distributed over an ellipse $30 \times 50 \mathrm{~km}$ in size, with a few outlying telescopes $150 \mathrm{~km}$ from the centre

\section{head trout from hungry sea lions}

Efforts to control the fish kill have gone on for years. State fish and game authorities have tried everything from throwing firecrackers at the sea lions and playing taperecorded orca sounds to removing some sea lions as far away as the Channel Islands off Santa Barbara, California. Most of the animals so displaced found there way back to Seattle, more than 1,000 miles up the coast.

Environmentalists claim that the sea lions are only one cause of the decimation of the steelhead, pointing out the degradation of the streams beyond the lakes, pollution and the rapid urbanization of the area. Reitan says that local Indians who fish for the trout claim the fish ladders at the locks were badly designed and that rebuilding them could make it possible for the steelheads to survive. And Bruce Sanford of the state Department of Fish and Wildlife says it is possible that if they removed the most voracious hunters, other sea lions might just improve their skills and replace them.

So why does the state want to kill the most aggressive animals? Local officials say that it takes several hundred fish to sustain the gene pool and even if the sea lions are only one cause of the decline, their appetites alone may wipe out the entire steelhead population. "It's gone beyond critical," Sanford says.

Unlike its close relative the salmon, which is also declining dramatically in the area, the steelhead spawns more than once and each year another brood tries the locks. Just because only 70 fish made it last time does not mean the fish is doomed, Sanford says. The task force's job is to determine whether evening the odds at the Ballard Locks will give the fish a chance to renew their population. A decision will be made at the end of the year.
Joel Shurkin and a densely packed region in the inner 400 metre. This would combine very high resolving power with high sensitivity, he says. The estimated cost today would be $\$ 300$ million, but Braun hopes this could come down to $\$ 100$ million with advances in technology.

Both of these ambitious projects would be able to study emission from gas in galaxies very early in the history of the Universe. Booth's telescope would study molecular gas from which stars form - a new but hot branch of astronomy. Braun's telescope would study atomic hydrogen in the clouds that condense to become galaxies.

Both proposals meet the rough guideline that any new telescope should realize a factor-of-ten improvement in sensitivity to be worth building. Booth's would have ten times the collecting area of the 30-metre telescope at Pico Veleta, Spain, and Braun's telescope would have 75 times the collecting area of the Very Large Array in New Mexico, and 14 times the collecting area of the largest single-dish radiotelescope in the world at Arecibo, Puerto Rico.

It is unlikely that Sweden or the Netherlands could fund these projects alone. Realistically, their funding will involve either many countries joining together to fund a World Radio Astronomy Observatory, or getting the Americans or Japanese to foot most of the bill.

In the United States, the National Science Foundation is already considering a proposal from the National Radio Astronomy Observatory to build the $\$ 150$ million millimetre-wave array (MMA) - a smaller and less powerful version of Booth's proposal. The United States is unlikely both to build the long-awaited MMA and to be a major partner in an international collaboration.

Japanese astronomers also have their own plans for a millimetre-wave array, but, in the tradition of Japanese science, it will cost more than other countries may be willing to pay. M. Ishiguro, of the Nobeyama Radio Observatory, estimates a cost of about $\$ 1$ billion for an array similar to the MMA, but operating to wavelengths as short as $0.375 \mathrm{~mm}$. Japanese radioastronomers are confident that they will have $\$ 300-\$ 400$ million to spend on their project near the end of the century, but will be hard pushed to attract others to contribute $\$ 600-\$ 700$ million, much of which would go to Japanese industry for development costs.

Last month, the general assembly of the International Astronomical Union in The Hague voted to set up a committee to investigate the best options for building a millimetre-wavelength array. The committee will be hard put to reconcile the conflicting interests of the governments that would pay for such an array and the scientists who would

use it.

Leslie Sage 